\title{
CONTROLANDO OS (ES)PAÇOS FEMININOS: DO CORPO DA MULHER MATERNA AO CORPO DA MULHER TRABALHADORA E \\ HIGIÊNICA
}

V. 8, n. 1 [12]

jan/abr (2016)

Dossiê: Gênero e Espaço II
Andrea Cristina Marques

Universidade Federal de Campina Grande - UFCG

andreacristinarmg@gmail.com

\section{Resumo}

O presente artigo objetiva mostrar como o espaço feminino passou por mudanças em seus discursos, analisando de que maneira essas mudanças acontecerem e fizeram parte da vida das mulheres. Como elas foram alvo dessas construções discursivas que as reduzia ao "ser materno" e de que forma esses discursos foram sendo transpassados por outros que as colocava em novos espaços, assim como o da mulher trabalhadora e da nova mãe, a mãe higiênica.

\section{Palavras-chave}

Espaço feminino. Discursos. Mudanças.

\section{Abstract}

This article aims to show how the female space has undergone changes in his speeches, analyzing how these changes happen and were part of women's lives. How were they target these discursive constructions that reduced to "being mother" and how these discourses were being pierced by others who put them in new spaces, as well as the working woman and new mother, hygienic mother.

\section{Keywords}

Female Space. Speeches. Changes. 


\section{O discurso médico do século XIX e a construção da mulher-materna}

A partir das teses dos médicos do século XIX feitas na Faculdade de Medicina do Rio de Janeiro, podemos ver que a puberdade foi considerada como o momento onde aconteceria uma "crise" da mulher, podendo ser perigosa tanto para as próprias mulheres como para a sociedade. Em uma das pesquisas sobre a puberdade feminina, o médico João das Chagas e Andrade, na tese, "A puberdade da mulher" do ano de 1838, item "ideia geral a respeito da mulher", coloca o que para ele seriam as características femininas, na puberdade, mostrando também a maternidade como algo naturalmente feminino:

[...] que fazem da mulher um ser essencialmente diferente do homem em função do papel que a natureza Ihe teria reservado. Tais características podem incluir peculiaridade quanto à voz, que é mais fraca, terna, doce e aguda; ao sono, menos profundo, de menor duração e mais perturbado; à digestão, que exige menor quantidade de alimentos; à respiração, que produz menos sangue; e mesmo à circulação, que é mais viva e dota melhor as artérias da bacia para fornecer mais sangue aos genitais (RHODEN, 2001, p. 117).

E as outras partes do corpo feminino também colaboravam para o entendimento de que maternidade era própria para elas, como a bacia, por sua largura, era propícia para a gestação. Características que segundo a medicina que estudava a puberdade feminina, significavam que o corpo da mulher era a lugar onde a maternidade residiria. Além disso, a mulher era considerada mais sensível do que o homem, tinha uma maior fragilidade, seus sentidos mais delicados, e as sensações mais vivas, "[...] seus olhos não suportam a luz forte por muito tempo e nem seus ouvidos aguentam o barulho de um canhão (RHODEN, 2001, p. 118)".

Por esses motivos é que a natureza já teria definido homens e mulheres para cada um preencher funções específicas. Diante disso, os saberes sobre as mulheres qualificaram como mais afetiva, enquanto o homem seria dotado de inteligência. Assim, para lidar com política e com as ciências, só havia chances para o homem, pois para tratar de questões públicas, era importante ser dotado de inteligência, enquanto a mulher tinha um perfil que se identificava com o mundo privado, particular.

Para sintetizar essa ideia dos discursos médicos do século XIX, podemos perceber a justificativa deles para designar homens e mulheres em suas funções sociais: 
Já vimos que, em conseqüência do tamanho e da conformação dos ossos, da pequenez e moleza dos músculos, todos os movimentos são morosos, e que por isso mesmo a vida sedentária se lhes torna como necessária, correspondendo no físico à fraqueza que temos notado no moral [...]. Além de não ter capacidade mental para o mundo público, a mulher também não tem capacidade física, só lhe restando permanecer no lar (RODHEN, 2001, p. 119).

O corpo das mulheres, que era considerado muito diferente, quando comparado ao dos homens, no que diz respeito à medicina, significava fragilidade e fraqueza, tipologias que eram levadas também para outros campos, como para a moral. Nesse sentido, as brincadeiras tinham que ser as mais cuidadosas, delicadas, como a de bonecas, por exemplo, que justificavam a natureza maternal das meninas, o que mais tarde, elas aplicariam aos seus esposos e filhos. As meninas eram também, segundo a medicina: dissimuladas, sabiam agradar, tinham o choro e a timidez, como alguns artifícios que usavam para atrair o sexo oposto.

O aparelho reprodutor feminino foi a forma mais marcante do saber médico afirmar a diferença entre homens e mulheres, pois os órgãos femininos eram dispostos de "uma maneira diversa daquela que estão no homem", (RHODEN, 2001, p. 119). E o médico João das Chagas e Andrade reforçava sua tese, dizendo ainda que ao homem cabia lidar com a natureza e com os entes animados através de sua inteligência. À mulher só restava o poder de sedução, em relação ao homem. E sobre as mulheres inteligentes, cultas e famosas, como toda exceção, dizia-se que tinham deslizado em seus deveres que a sociedade tinha Ihes imposto, como os cuidados com o lar e com a família. E assim à mulher caberia uma maior responsabilidade na procriação.

[...] Ela nos fornece o gérmen do ovo. É dentro dela que esse gérmen se desenvolve e é nutrido durante toda a gestação. E é também à mulher que cabe parir e amamentar. Para a realização de todos esses atos da geração, o corpo feminino dispõe de quatro aparelhos. O primeiro é o da germinação e compõe-se dos ovários e trompas (RHODEN, 2001, p. 119).

Ainda fariam parte dos quatro aparelhos do corpo feminino, o da gestação, composto pelo útero, onde o feto se desenvolveria. O terceiro aparelho seria o da copulação, considerado o órgão mais importante. Através dele, a mulher conseguiria manter a função de perpetuar a espécie, para os médicos. O quarto e último aparelho, segundo os médicos, era aquele destinado à geração, e foi nomeado de lactação. Dessa maneira, a reprodução é apresentada como uma função eminentemente da 
mulher. Logo, não tinha necessidade de diferenciá-la em relação ao papel exercido pelo homem (RHODEN, 2001, p. 120).

Segundo o médico João das Chagas de Andrade a puberdade seria uma fase onde a menina começa "[...] a respirar o doce e imperioso sentimento da reprodução". Nessa época da puberdade é que a menina estaria sendo preparada pela natureza para sua função reprodutiva, pois iria começar a menstruar, mudança física que mostrava que seu corpo já estava pronto para a maternidade. Seria também nessa fase que, segundo a medicina do século XIX, apareciam as perturbações como a histeria, a loucura, a ninfomania. E para que essa desarmonia física não acometesse as meninas na puberdade, elas tinham que seguir regras de higiene que impedissem essas manifestações. (RHODEN, 2001, p. 122).

Outros médicos do século XIX, como o doutor José Joaquim Firmino Júnior, mostram uma continuidade nas definições relativas às características que diferiam homens de mulheres, dizendo que a função reprodutiva, o repouso e a quietude, eram questões próprias para a mulher e o poder de raciocínio, a força física, e o movimento para o homem. Essa seria a ordem natural das coisas para a medicina da época: homens seriam racionais e fortes, enquanto as mulheres emocionais e frágeis.

Nesse sentido, as teses médicas desse período afirmavam que entre homens e mulheres não poderia haver igualdade de funções, pois a vida da mulher convergiria para um único fim, a reprodução da espécie, sendo uma época em que a menina deixava de viver para si, se preparando apenas para a reprodução, para os filhos, que um dia iria deixar a posteridade. E por ser responsável pela reprodução da espécie, é que as mulheres ganharam ares de divindade, era como se fossem quase Deusas, porque davam a vida, a luz. (RHODEN, 2001, p.123).

Nesse caso, a mulher, segundo o discurso higiênico, nascera para a família e para a maternidade e nunca para outras coisas. Sobre ela dizia-se:

A mulher (...) não é feita para figurar no liceu ou pórtico, nem no ginásio ou hipódromo; e seu destino sendo o de estabelecer o encanto e o doce da família ainda sua vida inteira não era muita para os numerosos cuidados que esta reclama." Os sinais de sua vocação eram imperceptíveis desde a mais tenra idade: "Com efeito desde a sua infância, a mulher começa a manifestar os doces sentimentos que devem sucessivamente tornar amante, esposa e mãe [...] (COSTA, 1979, p. 239).

Por ter essa tarefa primordial, o dom de dar a vida a alguém, é que as mulheres não poderiam se ocupar com outras questões, como a intelectualidade, diziam os médicos. A mulher seria muito sensível, mas não para usar a racionalidade, 
como os homens, cabendo a ele o papel mais produtivo, racional. Uma mulher não poderia, por exemplo, pegar em armas ou se dedicar às funções ditas masculinas, pois prejudicaria sua função social, entrando no mundo masculino.

Essas diferenças só se tornariam mais expressivas mesmo com a puberdade, pois nessa fase é que os contornos femininos surgiam demonstrando que a menina estava pronta para se tornar mãe. Os médicos por sua vez esclareciam essa preparação do corpo feminino para a maternidade, sempre comparando ao masculino. Sendo que na puberdade o corpo da mulher chegaria à estatura que lhe era própria, menos elevada que a do homem; a cabeça era menor do que a do homem e arredondada, coberta por cabelos leves e flexíveis; o colo era mais longo; o tórax era menos alto; as clavículas menos curvas; os seios mais volumosos; a bacia tinha a capacidade necessária para dar lugar ao parto; as coxas eram mais curtas e as pernas menos longas. E no final da puberdade, os ovários cresciam e logo vinha a secreção vaginal o que demonstrava que a menina já havia virado mulher, podendo naquele momento se tornar mãe.

As características femininas, mostradas pela medicina do século XIX, colocavam a puberdade como um momento ímpar para a vida da mulher, momento esse em que delimitava a transformação de uma menina em uma mulher-mãe. Para eles, a mulher só perceberia o sentido de sua vida a partir da puberdade ${ }^{1}$, quando seu corpo passaria pelas mudanças que mostrariam o caminho a seguir por elas, o da gestação, do parto, da amamentação, dos cuidados com filhos e marido.

O corpo feminino na puberdade acordaria do sono em que se encontrava e se preparava para o amor. Tal preparação para o amor dita pelos médicos dizia respeito às mudanças ocorridas no período da puberdade, quando surgiam os pelos, o aumento da vagina, o clitóris, e o hímen se distenderia, marcando a virgindade, modificações pelas quais o corpo da menina passava, na puberdade, e que, segundo os médicos, diziam que ela estava pronta para o amor ou o sexo. Deixando claro que a puberdade era uma época de preparo do corpo para o amor e o sexo, mas também era colocado pelos estudos médicos da época que nesse momento surgia, na mulher, sentimentos como o pudor, a alegria, a tristeza, a cólera e a melancolia. Essa gama de sentimentos deixava as mulheres ainda mais irresistíveis, pois lhe davam certo charme, diziam os médicos. (RHODEN, 2001, p. 127).

${ }^{1} \mathrm{O}$ doutor José Joaquim Firmino Júnior em sua Tese "Mulher em geral: menstruação e suas causas" argumentou que somente na puberdade a mulher deixaria de significar um "equívoco", nesse momento as mulheres passariam a ter consciência de seu sexo em que seu corpo era preparado para a reprodução da espécie. RHODEN, 2001, op. cit., p. 125. 
A menstruação seria ainda "a bússola da mulher", época que marcaria um novo momento da vida da mulher, onde a moça começaria a sentir enjoos, fadiga, dores, sensação de cabeça pesada, vertigens e entristecimento. Quando passavam a menstruar, aumentavam os problemas, nas moças que viviam nas cidades, pois nelas as menstruações ocorriam antes, como colocavam os médicos, do tempo projetado naturalmente, enquanto que as moças que moravam no campo tinham sua menstruação num período mais adequado, tempo previsto pela natureza, era uma relação entre corpo e natureza, interpretada por alguns médicos. Um problema que poderia ocorrer, na época da puberdade das meninas, e pelo que falavam os médicos em suas teses, e que ocorria bastante, era a prática da masturbação. Os colégios, para os médicos, eram um grande reduto da masturbação, uma prática que para eles era muito prejudicial para ao sistema reprodutivo feminino, a "viciosa" masturbação, que para os médicos irritava os órgãos genitais, acelerando o aparecimento das funções uterinas. (RHODEN, 2001, p. 128).

O que também aumentava a exaltação erótica das moças. Por isso, era preciso tirá-las dos colégios, nesse período para evitar essa prática, já que dentro dos colégios se tornava impossível vigiá-las. Assim, os médicos receitavam distrações como leituras de história, geografia, belas letras, além de aplicações de religiosidade e moral. Também receitavam uma vigilância ativa, juntamente com uma dieta especial com vegetais, exercícios, dormir tarde e acordar cedo, para gastar as energias, tudo isso fazia parte das prescrições.

A chegada da menstruação, tarde demais, significava problemas, diziam os médicos, pois a moça não estaria bem de saúde. Para elas, o regime indicado pelos médicos era um pouco diferente do das moças que tinham muita energia para gastar deveriam tomar banhos de mar, águas minerais, tônicos, sangrias, habitar lugares arejados e secos, mudar de ares, passear, viajar, beber vinhos moderadamente, se alimentar adequadamente, com alimentação fortificante e ainda tinha uma prescrição médica um pouco excêntrica, que consistia na aplicação de choques elétricos nas partes genitais, assim teria fim a apatia e falta de energia próprias do aparelho genital.

Por isso, os médicos se preocupavam tanto com o período da menstruação, que não poderia ser tardio ou cedo demais, para que não ocorresse nenhum problema com o sistema reprodutivo das moças, pois elas deveriam seguir as regras da higiene médica, visando uma boa conformação dos órgãos genitais. Ou seja, a sexualidade feminina estava sempre ligada à reprodução. (RHODEN, 2001, p. 130). 
As meninas-moças tinham que estar preparadas para o momento em que a menstruação chegasse, para que, não ficassem envergonhadas, quanto a isso. Algumas ignoravam que a natureza um dia modificaria seu corpo, diziam os médicos, tornando-as mulheres e muitas vezes por ignorar o momento da menstruação ou vergonha, escondiam de seus familiares o que estava acontecendo. Por esse motivo, as mães foram chamadas a prepará-las para a chegada da puberdade. Elas deveriam ser prudentes, sensíveis, zelosas para que suas filhas ficassem bem com relação à saúde. Tornaram-se assim, colaboradoras dos médicos que thes passavam os ensinamentos e elas repassavam para as filhas, detalhes como:

[...] não tomar banhos com água fria, se abster de bebidas frias, geladas, excitantes ou alcoólicas, como sorvetes, café, chá ou licores: elas evitarão com todo cuidado cheiros fortes que algumas vezes se acham espalhados na atmosfera: poder-se-ia citar um sem número de casos de moças incomodadas grandemente, por terem a imprudência de habitar em quartos pintados de novo, e dormir onde há rosas, jasmins, e outras flores de cheiro ativo. É prudente que não se sentem sobre corpos frios e úmidos: os panos empregados em receber os sangues das regras, à medida que se escapa das partes genitais, deverão ser sempre bem secos, e aquecidos brandamente, antes de serem empregados (RHODEN, 2001, p. 133).

Contudo, as maiores exigências dos médicos do século XIX eram mesmo com relação à educação dada pelos pais às filhas. Para que a moça fosse educada sem fugir às condutas prescritas, as mães não deveriam proibi-las de uma educação intelectual mais aprimorada. Não deixá-las estudar demais, dedicarem-se muito às leituras, o que nos dizeres médicos, poderia gastar muita energia, que tinha que ser guardada para ser empregadas no amadurecimento do órgão reprodutor. O que poderia causar a demora no aparecimento da primeira menstruação, nesse caso, 0 esforço mental poderia ser um problema para a moça que entrava na puberdade. Nesse sentido diziam os médicos:

(...) A espécie de império, que exercem na sociedade, exige que elas não sejam ignorantes; porém não Ihes é devido o mesmo grau de instrução dos homens, cujos destinos partilham e embelezam. 0 estudo moderado das artes de recreação é o único que Ihes convém; porém somente como meio de adoçar as tristezas, suavizar o aborrecimento da solidão, lançar sobre o curso de sua vida doces e agradáveis distrações, de variar enfim os prazeres distraindo-os em seus trabalhos (...) (RHODEN, 2001, p. 134)

Em outro momento da vida da mulher, aquele que anuncia a chegada da menopausa, vemos o que era dito, segundo o saber médico, sobre essa fase 
denominada pelos médicos de "idade crítica", porque a preocupação deles era com o desaparecimento da capacidade reprodutiva, na vida da mulher. ${ }^{2}$ É perceptível que houve uma construção feita pela medicina sobre a puberdade que afirmava ser 0 momento em que a mulher se tornaria bela, enquanto na menopausa, aconteceria o contrário, a mulher perderia todos os atributos belos que teria conseguido com a puberdade.

A menopausa seria então o inverso da puberdade, onde "[...] os ovários se atrofiam, diminuindo em todos os seus diâmetros e apresentando o seu invólucro enrugado. O útero parece passar a um estado de vida vegetativa, assim como as mamas" (RHODEN, 2001, p. 135).

A "idade crítica", como dizia os médicos, era colocada por eles como um momento de decadência da vida da mulher, um período onde terminava a missão que a natureza encarregava à mulher: a de gerar vidas. Pois,

[...] a idade crítica muito a propósito denominada inferno das mulheres, fazendo-as passar de uma estação de gozos, e de alegria a uma época de terríveis padecimentos, as submerge por todo o resto de sua vida em um vasto golfo de penalidades e aflições. Todas as suas belezas desaparecem como por encanto; a nitidez de sua lisa pele foge; seu formoso, e imberbe rosto cobre-se de alguns pelos no mento, e lábios; a grande abundancia de tecido celular subcutâneo some-se; os seus músculos murcham; e suas arredondadas formas tornam-se rugosas, e ásperas (RHODEN, 2001, p. 135).

Na menopausa, a mulher parecia estar num estado de decrepitude, decaindo. Os médicos, em suas teses que tratavam dessa fase da vida feminina, falavam sobre esse momento como sendo de tristeza para a mulher, onde a mulher ficava abatida, lânguida, os tecidos e a pele, ficavam flácidos, perdendo suas formas graciosas; a voz tinha alterações, os olhos perdiam sua vivacidade, os cabelos a espessura, a língua tornava-se seca, os seios moles, enfim, "[...] todo esse corpo cai numa espécie de deterioração, marchando a largos passos para a velhice" (RHODEN, 2001, p. 136).

Nesse período, segundo a medicina, a digestão tornava-se lenta, o apetite diminuía, a mulher urinava em abundancia, sentia frios súbitos e espontâneos, tinha secreção abundante da saliva, diminuição da transpiração cutânea, constipação do ventre, etc. Somado a essas características físicas, o moral feminino, pelos dizeres médicos, sofria mudanças também:

\footnotetext{
2 Mesmo assim, foram produzidos poucos trabalhos acerca do tema da menopausa durante 0 século XIX, aparecendo mais trabalhos sobre esse tema, já no final do século. O que pode estar relacionado à valorização feminina, quase que exclusivamente, no período reprodutivo. RHODEN, 2001, op. cit., p. 134-135.
} 
[...] A mulher torna-se morosa, inquieta, taciturna, muito sensível; o prazer the é indiferente, agasta-se com seus filhos e marido sem causa alguma; o repouso tem para ela mais encanto, do que o exercício; sua vista torna-se muito sensível, e é a este aumento de suscetibilidade dos nervos óticos (...) (RHODEN, 2001, p. 136).

Haveria uma "perturbação" das funções femininas, na menopausa: perda dos vários atrativos que uma mulher tinha e de suas capacidades. O discurso médico era bastante radical, quando se tratava de falar sobre essa fase. Assim, dizia que a mulher na menopausa já teria cumprido seu destino, sua missão sobre a terra, a idade dos prazeres terminava, sendo substituída por uma felicidade tranquila, sem paixões. A mulher na menopausa era agora uma "divindade secundária", sem adoradores, pois "[...] A verdadeira e santa amizade preenche o lugar desses loucos amores de sua mocidade, os prazeres domésticos e a felicidade de ver seus filhos possuindo uma educação religiosa, moral e intelectual, completam toda sua dita" (RHODEN, 2001, p. 136).

$\mathrm{Na}$ tese do ano de 1878 , de José Teixeira de Coelho, redefine algumas posições acerca do papel da mulher na sociedade, inovando, para a época, ao colocar que a mulher não seria mais considerada simples instrumento de procriação, ocupando, segundo o médico, um lugar mais "honroso" dentro da sociedade, ajudando o homem no seu engrandecimento. ${ }^{3}$

Porém, o "novo" lugar, que as mulheres ocupam naquele momento, estava relacionado a mais uma obrigação que era a de também educar os filhos e se responsabilizar pela transformação deles em indivíduos saudáveis e bons cidadãos para a pátria. Observamos que nesse final de século houve uma valorização da mulher sem precedentes no que se refere à reprodução de uma ordem com base na família, que teve início dentro da medicina. A mulher tornou-se importante como uma reserva moral dentro da sociedade, levando em consideração que estava mais próxima do que o homem da religião, do amor, da abnegação, da dedicação aos outros. (RHODEN, 2001, p. 137).

Se antes, a mulher tinha como atribuição 'dar a luz', no final do século XIX, mais essa atribuição lhe seria dada a partir dos discursos vindos das teses médicas, 0 que Ihes dava uma responsabilidade ainda maior quanto aos filhos.

${ }^{3}$ Porém, vemos que a mulher continuou sendo coadjuvante nas relações entre ela e o homem. 


\section{O controle da natalidade, o trabalho fora do lar e a mulher higiênica}

Nas últimas décadas do século XIX, tornou-se preocupação do discurso médico dar à mulher um papel social que não se restringisse apenas à maternidade, à procriação, questão que pode ser observada a partir da revisão que eles fizeram, reavaliando o que suas teses tinham dito anos antes, refletindo a tendência da época de que o casamento teria como consequência a redefinição do valor atribuído à mulher. Embora essa revisão continuasse levando a mulher a viver somente as funções de mãe e esposa, dentro da vida familiar.

Levar a mulher a contribuir cada vez mais em relação à família seria necessário para que o casamento gerasse crianças saudáveis, que resultariam em cidadãos úteis à nação. Por isso, os médicos afirmavam que somente o casamento saudável e ordenado poderia organizar a sociedade, pondo fim a qualquer risco acerca da reprodução da espécie que deveria ocorrer da melhor forma. Somente através dele, homens e mulheres trariam o equilíbrio das raças e o progresso da civilização. ${ }^{4}$

Nesse sentido, a medicina do século XIX passou a investir no controle da natalidade, na tentativa de controlar o corpo feminino, considerando que as mulheres dessa época faziam uso de contraceptivos como camisinhas, pessários (dispositivo que cobria o colo do útero impedindo a fecundação), diafragmas, seringas e abortivos. Além dos métodos tradicionais como o coito interrompido que era recorrente. ${ }^{5} \mathrm{O}$ que os médicos higienistas não viam com bons olhos, pois além dessas práticas a do aborto também passou a ser contínua para as mulheres que procuravam controlar sua natalidade. ${ }^{6}$

O controle do corpo pelas mulheres, por meio da contracepção, trazia vários problemas, como a diminuição no número de filhos. ${ }^{7}$ Essa queda na taxa de

\footnotetext{
${ }^{4}$ Esse pensamento estava atrelado ao pensamento higiênico e eugênico que, nesse período, circulava pela sociedade, na preocupação de construir uma raça pura, forte, saudável, que levasse a uma nação perfeita.

${ }^{5}$ Essas práticas de contracepção foram bastante utilizadas já no século XIX pelas mulheres e eram anunciadas segundo Rhoden (2003) em jornais e revistas vendidas em lojas e farmácias e até mesmo de porta em porta. Nos Estados Unidos desse período, a prática do aborto se tornou uma questão polêmica, principalmente a partir do impacto das campanhas feministas.

${ }^{6}$ A partir da pesquisa de Rhoden (2003), foi perceptível que a prática de abortos foi usada principalmente pelas mulheres de classes menos favorecidas, que teriam menos acesso aos contraceptivos.

${ }^{7}$ Embora Rhoden coloque que existia também como motivo para a baixa natalidade no século XIX, há a questão da difusão dos valores e atitudes com relação a uma vontade dos casais de diminuir seu número de filhos ou espaçar os nascimentos deles.
} 
natalidade foi observada pela medicina como um grande problema, pois além dessa queda na natalidade, o que diminuía a quantidade de futuros cidadãos que garantissem o progresso da nação, havia também o fato de que as mulheres estavam se tornando mais emancipadas, preocupando as autoridades no assunto quanto à liberdade sexual, que surgia em decorrência do controle na reprodução feminina.

Controlar o corpo, tendo controle do número de filhos gerados, trouxe também para a mulher a possibilidade de trabalhar fora do lar, o que não agradava aos médicos. Assim, as grandes famílias iam perdendo espaço para as famílias de poucos membros.

E um dos motivos que influenciava nas mudanças ocorridas com as famílias seria a questão referente ao trabalho feminino, que basicamente diferenciava mulheres pobres das mulheres ricas, já que ambas trabalhariam por motivos diferentes: onde geralmente as mulheres mais pobres saíam de seus lares em busca de trabalho para poder colaborar financeiramente com seus maridos, isso quando os tinham; já as mulheres ricas quando iam trabalhar muitas vezes era em atividades filantrópicas, beneficentes, de caridade. As mulheres pobres, na maioria das vezes, se empregavam como domésticas ou nas fábricas de roupas, de chapéus, de sapatos, de vassouras, cestas, velas, sabão. Outras mulheres, com um pouco mais de instrução trabalhavam em funções como de professora, secretárias, enfermeiras.

A inserção das mulheres, no mercado de trabalho assalariado, ganhou força mesmo a partir da primeira guerra mundial. Para Freire (2009), no Brasil as mulheres passaram a trabalhar fora de seus lares no pós-guerra, entre os anos de 1920 e 1940, onde elas passaram a disputar o mercado de trabalho com os homens.

Mas, mesmo o trabalho feminino, sendo feito pelas mulheres pobres ou ricas, era considerado:

[...] tão ameaçador quanto outras atitudes emancipatórias, uma vez que deslocava os papéis conjugais destinados por Deus: a autoridade ao marido e à obediência à esposa. A "invasão" do espaço urbano através do trabalho externo assalariado não reduziu as cobranças e exigências morais dirigidas às mulheres [...] (FREIRE, 2009, p. 61).

Portanto, questão de conciliar o trabalho assalariado com o trabalho do lar, principalmente nas classes pobres, tornou-se desafiador para os intelectuais e reformadores da República, que se preocupavam com o abandono dos filhos pelas mães que trabalhavam fora do lar, pois, assim, o projeto dos papéis femininos, na família nuclear, estava sendo pulverizado. 
Trabalhar fora de casa, assim como sair da vida doméstica, significava para os teóricos, médicos e economistas da época que a mulher destruiria a família, tornando os laços familiares mais frouxos, debilitando também a raça, porque os filhos iam crescer soltos, sem a vigilância das mães. Essas, por sua vez, deixariam de ser mães dedicadas e esposas carinhosas, trabalhando fora de seu lar. Na época, se falava que a mulher que trabalha fora, se desinteressava pelo casamento e pela maternidade. Assim,

[...] De que modo as mulheres que passavam a trabalhar durante todo o dia, ou mesmo parcialmente, poderia se preocupar com o marido, cuidar da casa e educar os filhos? O que seria de nossas crianças, futuros cidadãos da pátria, abandonados aos anos mais importantes de formação de seu caráter? (RAGO, 1997, p. 585).

Segundo a medicina que circulava durante o século XIX, era preciso lutar contra o trabalho da mulher fora do lar, pois o trabalho seria uma ameaça à honra feminina. Operários militantes, juristas, jornalistas, diziam que a fábrica, lugar onde geralmente muitas mulheres trabalhavam entre o século $\mathrm{XIX}$ e início do $X X$, eram "antros de perdição", "bordéis", e as trabalhadoras vistas como pessoas passivas e indefesas. 0 que levava muitas vezes a mulher a crer que seu lugar era a esfera privada. ${ }^{8}$ Por isso, para os defensores das altas taxas de natalidade, como a política familialista e natalista francesa do século XIX, converteu-se no remédio que permitiu mudar clima moral do país, marcado pela união livre, abandono da família, divórcio, egoísmo conjugal, aborto, leviandade sexual e deboche. (RHODEN, 2003, p. 34).

Era preciso combater o individualismo excessivo por meio da valorização da família, que estava acontecendo por causa do controle do corpo pelas mulheres, ameaçando a construção de uma pátria saudável, forte, higienizada. E esse combate à emancipação feminina seria feito por meio da valorização da família e da maternidade. Portanto, era necessário que fossem tomadas medidas que reforçassem o ideal de família, combatendo o aborto, o divórcio, o trabalho feminino, dando incentivos às famílias grandes e privilégios aos chefes de família. Para aumentar o combate à emancipação das mulheres, as organizações e movimentos feministas que defendiam os direitos delas foram duramente atacados.

\footnotetext{
8 Para justificar e manter a mulher, na esfera do lar, com a ajuda do discurso de uma "natureza feminina", os médicos escreveram também sobre o sexo antes do casamento, condenando para as mulheres e liberando para os homens, porque segundo eles, esses últimos teriam o instinto sexual mais intenso que as mulheres, que por sua vez tinham um amor mais ideal, sentimental. Por isso, elas tinham uma relação tão profunda com a família, com os filhos.
} 
A mulher dentro do casamento tinha uma grande missão, já que desempenharia os deveres de mãe e filha. E a medicina acreditava ainda que contribuiria muito para o "engrandecimento e a satisfação da família", ao educar seus filhos, elevando a família a um status moral que uma mulher conseguiria. Pois a sociedade, segundo as teses médicas, proviria da família, que tinha, na mulher, sua fonte de harmonia. A mulher deixava de ser apenas reprodutora, acumulando mais uma função e não saiu do mundo doméstico, já que as virtudes atribuídas a ela referiam-se à vida privada do lar e da família.

Construindo a ideia de uma "natureza feminina", os discursos médicos justificavam essa "missão" da dedicação exclusiva ao lar que as mulheres teriam e baseando-se, na questão física ou biológica da mulher, na sua capacidade de gestar, parir, amamentar e menstruar. Desse modo, decorreria daí as justificativas para que o corpo feminino fosse relacionado diretamente à maternidade e ao instinto maternal. ${ }^{9}$ Assim, buscava-se com essa justificativa reafirmar a relação mulher, à maternidade, enquanto uma identidade fixa, eterna. O amor incondicional da mãe pelos filhos seria natural e negava-se à cultura como mediadora dessa construção identitária para as mulheres.

$\mathrm{Na}$ construção da natureza feminina pesquisada por Meloni (2002) foi perceptível à influência de teses médicas européias sobre essa construção, que tinham servido de base para os estudantes brasileiros do curso de medicina concluir suas teses. Os médicos brasileiros procuravam entender o aspecto biológico do corpo feminino para saber suas especificidades. O corpo feminino ficaria sob a tutela da medicina, enquanto saber, e seus cuidados ficariam subordinados ao controle do profissional da medicina.

A mulher era diagnosticada pelos médicos como possuidora de um corpo natural, essencialmente maternal, reprodutivo e sua sexualidade deveria estar relacionada a essas características. Aquelas que se desviassem dessa norma eram nomeadas de "degeneradas", "desnaturadas", pois a natureza feminina tinha que ser procriadora e maternal. Nesse caso, a sexualidade feminina também tinha que estar de acordo com os discursos médicos que afirmavam que ela era procriadora por

9 Embora possamos afirmar que segundo alguns estudos sobre a maternidade, como o de Badinter (1985), que questões biológicas ou físicas presentes nos corpos das mulheres podem não ter o mesmo significado em outras culturas, revelando-se então como construções sociais que dependem do contexto em que estão inseridas. MELONI. Elizabeth. A medicalização do corpo feminino. Rio de janeiro: Fiocruz, 2002, p. 31-32. 
excelência. A mulher teria uma "essência" fisiológica relacionada aos seus sentimentos, comportamentos e atitudes.

Na construção da mulher ideal, higiênica, a mulher passou por um período de crítica, sendo reduzida ao confinamento doméstico, portanto educá-las era um passo primordial, o que resultaria na própria educação de seus filhos e, consequentemente, na concretização do projeto idealizado pela campanha higienista. Seguindo a orientação desse projeto de uma educação voltada para a mulher, os médicos explicavam o motivo pelo qual elas tinham que ser educadas, dizendo que as mesmas não tinham desenvolvido sua capacidade cerebral por ter se servido pouco dele e ainda afirmava: "A educação das mulheres é necessária, a mulher precisa ser educada para poder educar os filhos [...]" (MELONI, 2002, p. 35).

Educando ${ }^{10}$ as mulheres, nascia a mãe higiênica, colonizada pelo saber médico. A mãe higiênica deveria ter todo um cuidado com os filhos, amamentando-os, numa relação amorosa com seu bebê. A amamentação foi uma das maneiras que os médicos encontraram para preparar, educar a mulher para se tornar uma boa mãe. Por isso, os médicos condenavam a prática do aleitamento materno mercenário ${ }^{11}$, afirmando que era um mal a ser combatido, pois as mulheres não deveriam fugir de sua vocação natural, de cuidar de amamentar seus filhos.

A "nova mãe" passava através desses discursos a desempenhar um papel fundamental no nascimento da família nuclear moderna. Segundo esses discursos, essa mãe moderna tinha que ser:

[...] vigilante, atenta, soberana, no seu espaço de atuação, ela se torna a responsável pela saúde das crianças e do marido, pela felicidade da família e pela higiene do lar, (...). A casa é considerada como o lugar privilegiado onde se forma o caráter das crianças, onde se adquirem os traços que definirão a conduta da nova força de trabalho do país. Daí a enorme responsabilidade moral atribuída à mulher para o engrandecimento da nação (RAGO, 1985, p. 80).

O discurso médico, além das teses para explicar e divulgar a necessidade da mulher no lar buscava também respaldo também dessa ideia de uma nova mulher

10 Para educar as mulheres, o ensino da educação física atuaria também na sua saúde corporal, proporcionando corpos sadios que gerariam crianças sadias. O desenvolvimento de uma sociedade sadia dependeria do desenvolvimento físico, intelectual, espiritual das mulheres. MELONI, 2002, op. cit., p. 36.

11 O aleitamento mercenário acontecia quando as mães deixavam seus filhos para ser amamentados por nutrizes, fossem elas amas de leite ou escravas. Isso era criticado pelos médicos do século XIX porque se tornava uma maneira pela qual eles conseguiam penetrar no interior familiar, redefinindo os papéis de cada pessoa. RAGO, Luzia Margareth. Do cabaré ao lar. A utopia da cidade disciplinar. Brasil 1890-1930. Rio de Janeiro: Paz e Terra, 1985. 
moderna na concepção do filósofo Jean Jacques Rousseau ${ }^{12}$, que afirmava que a mulher não poderia se desviar do seu caminho já traçado pela natureza, a família e a maternidade. Nesse aspecto, a maternidade era vista enquanto sacerdócio, sendo a boa mãe, a que cuidava de seus filhos, que os aleitava considerada uma santa, totalmente dessexualizada, pura. ${ }^{13}$ Essa aproximação da mulher-mãe a uma santa serviu para dirigir mais ainda as mulheres ao lar e à procriação.

Essa dessexualização ${ }^{14}$, vivida pelas mulheres-mães, ficava clara no cotidiano das mulheres, quando os médicos, no período em que elas estavam gestantes, restringia ao máximo suas relações sexuais, a fim de evitar abortos e outros problemas que poderiam acontecer, durante a gestação. Por que "A mulher grávida é o santuário que abriga o germe do futuro cidadão. Todo o contato impuro lhe será profanação" (COSTA, 1979, p. 262).

Quando amamentava, a mulher-mãe passava por questões que a dessexualizavam, como a questão das relações sexuais que deveriam ser evitadas, sempre que fosse possível, para que não acontecesse outra concepção. E outra gestação, poderia trazer problemas para a amamentação, seria inconveniente, diziam os médicos. Assim, a amamentação colocou a sexualidade da mulher a serviço da família. A sexualidade feminina, a partir do momento da amamentação, teria rédeas curtas, período em que seu trânsito seria o mínimo possível, além do que tinha dentro do lar.

E quando não amamentava, a mulher era responsabilizada pelos médicos em dissolver a família, provocando o afrouxamento dos laços familiares, laços entre pais e filhos, esposo e esposa e entre os irmãos; enquanto isso, a mulher que amamentava estreitava esses laços e trazia a alegria ao lar. Através do ato de amamentar depositava-se, na mulher, a responsabilidade da unidade familiar. A mãe que amamentava tinha, portanto, a grande função de ser o esteio da família.

Para Costa (1979), amamentar o filho seria tanto uma maneira de proteção que a mãe daria ao filho como também poderia ser um regulador da vida da mulher-mãe,

12 Jean-Jacques Rousseau, foi um importante filósofo, teórico político, escritor e compositor. Autodidata suíço do século XVIII é considerado um dos principais filósofos do Iluminismo e um precursor do romantismo. Segundo Rousseau, o corpo e a alma femininos são governados pelo sexo. RHODEN, 2001, op. cit., p. 29.

${ }^{13}$ Segundo Margareth Rago, o discurso religioso que relacionava as mães às santas também construía o seu contraponto, a figura da prostituta, que era sensual, pecadora, a Eva, que era a perdição do homem. RAGO, 1985, op. cit., p. 82.

${ }^{14}$ A dessexualização [...] se dá pelo deslocamento do investimento libidinal que originalmente incidia sobre o objeto sexual, passando agora a incidir sobre um objeto não sexual. CF. http://www.psicolatina.org/09/vicissitudes.html, acessado em 24/02/2014. 
que deveria estar ocupada, não ociosa. A amamentação do filho seria então uma maneira de prendê-la dentro de casa, não podendo fazer concorrência para os homens que se ocupavam com a vida pública.

Amamentar tinha assim um objetivo disciplinar na vida das mulheres-mães, pois o ato da amamentação era uma utilização higiênica que a mulher fazia do seu tempo livre dentro de casa. Ficando também livre dos "perigos do ócio e dos passatempos nefastos à moral e aos bons costumes familiares", tudo isso pelo medo que se tinha das mulheres ficarem entusiasmadas com a independência feminina que, neste momento, se emancipava do patriarcado colonial.

Um dos motivos para a cobrança da disciplina era o grande medo da autonomia feminina, sendo uma questão que preocupava demais a sociedade, já que com ela, a mulher poderia ultrapassar o limite da segurança social, indo de encontro com os limites impostos pelos higienistas a essa independência. Ser independente não significava uma coisa muito boa para a sociedade que pregava os ideais da higiene, porque o melhor seria que o espaço das mulheres fosse o lar, sem extravasar as fronteiras de casa, sendo a mulher-mãe imaginada pela normatização social. Alguns motivos, colocados pelos médicos higienistas, mostram o que se pensava sobre as mulheres que conseguissem autonomia.

\begin{abstract}
Emancipada intelectual e profissionalmente, a mulher comprometia o pacto "machista" firmado entre a higiene e o homem (...). A mulher que trabalhava punha em risco os termos do acordo. Tornava-se economicamente liberada do marido e intelectualmente equiparada ao homem. Sobre ela o "machista" não tinha o mesmo poder e a mesma ascendência. Automaticamente, a crença e as condições materiais para continuar exercendo sua "superioridade natural" ficariam abaladas. Sem a "inferioridade da mulher" o machismo perderia parte de seu sentido (COSTA, 1979, p. 260-261).
\end{abstract}

Fora do lar, a mulher quebrava ainda a coesão familiar, afrouxando os laços familiares, ou melhor, os laços que prendem os pais aos filhos, os filhos aos pais, esposo à esposa. Nesse sentido, o aleitamento materno estreitava os laços da família e trazia alegria ao lar.

$E$, a partir dos discursos médicos do século XIX, as mulheres passariam a estar sempre ligadas aos temas, à sexualidade, à reprodução, e à maternidade, como se estivessem presas às funções sexuais e reprodutivas. Um exemplo disso é que se em um casamento não fosse gerado os filhos, o problema seria uma falha reprodutiva feminina e dificilmente masculina. O que era uma indicação de que teria ocorrido alguma perturbação da mulher, como por exemplo, desejo sexual exagerado fora dos 
limites convencionais, ou a não aceitação do casamento e da maternidade pela mulher. Essas perturbações eram entendidas como um problema, um tipo de doença da mulher, porque não era visto como um modelo de comportamento característico dela, podendo ser sintomas da fuga do seu "destino natural", ser mãe. (RHODEN, 2001, p. 113).

Portanto, era responsabilidade da mulher a unidade familiar. A vida sexual feminina deveria ter comprometimento para que não andasse sem regras pela sociedade. E, para manter este compromisso social, era preciso que ela soubesse unir com perfeição o sexo, a estabilidade conjugal e a responsabilidade com os filhos, requisitos básicos para uma vida familiar harmoniosa.

\section{REFERENCIAS}

COSTA, Jurandir Freire. Ordem médica e norma familiar. Rio de Janeiro: Graal, 1979.

FREIRE, Marta de Luna. Mulheres, mães e médicos. Discurso maternalista em revistas femininas (Rio de Janeiro e São Paulo, década de 1920). Tese de doutorado em História das ciências e da saúde. Rio de Janeiro: Fiocruz, 2006. 336 pgs.

. "Ser mãe é uma ciência": mulheres, médicos e a construção da maternidade científica na década de 1920. Revista História, ciências, saúde Manguinhos. Rio de Janeiro, v. 15, junho, 2008.

FREITAS, Patrícia de. Corpos de mulheres em (Re) vista. A representação da menopausa na Revista de Ginecologia e d' Obstetrícia 1907-1978. Tese de Doutorado em História Cultural. UFSC, Florianópolis. 413 pgs. 2005.

. A mulher é seu útero. A criação da moderna medicina feminina no Brasil. Revista Antíteses, vol. 1, n. 1, jan.- jun. de 2008, pp. 174-187.

MELONI. Elizabeth. A medicalização do corpo feminino. Rio de janeiro: Fiocruz, 2002.

RAGO, Luzia Margareth. Do cabaré ao lar. A utopia da cidade disciplinar. Brasil 1890-1930. Rio de Janeiro: Paz e Terra, 1985.

RHODEN, Fabíola. Uma ciência da diferença. Sexo e gênero na medicina da mulher. Rio de Janeiro: Fiocruz, 2001. 
- A arte de enganar a natureza. Contracepção, aborto e infanticídio no início do século XX. Rio de Janeiro: Fiocruz, 2003. 